\title{
STUDIES ON THE KINETICS OF GLUCOSE UTILIZATION
}

\author{
By C. J. HLAD, JR., H. ELRICK, AND T. A. WITTEN with THE tECHNICAL ASSISTANCE OF \\ A. SMITH, Y. ARAI AND T. BOW

\begin{abstract}
(From the Radioisotope Service of the Veterans Administration Hospital and Departments of Medicine and Physiology, University of Colorado Medical Center, Denver, Colo.)
\end{abstract}

(Submitted for publication January 10, 1956; accepted June 18, 1956)

During recent years quantitative mathematical procedures have been applied to glucose utilization $^{1}$ studies in an attempt to replace less exact glucose tolerance tests. Examples of this type of work have been reported by Greville (1), Amatuzio, Stutzman, Vanderbilt, and Nesbitt (2), and Jokipii and Turpeinen (3). The techniques employed by these investigators were somewhat different, but the results indicate that the disappearance of glucose from the blood during glucose infusion or subsequent to a single I.V. glucose load follows an exponential function with respect to time. Greville (1) reported an empirical equation describing the behavior of blood glucose following a sudden glucose load. This equation contained a constant term representing an eventual equilibrium glucose level which was not necessarily equivalent to the initial fasting level. Amatuzio, Stutzman, Vanderbilt and Nesbitt (2) employed a similar equation in which they used the initial fasting level as the constant term. The latter's experimental results indicated that the specific rate constant ${ }^{2}$ for glucose utilization was reproducible in the same patient and remained constant for two different glucose loads.

In an effort to avoid the unphysiologic blood glucose levels obtained with sudden glucose loading, Jokipii and Turpeinen (3) used a continuous infusion technique. Their results indicated that various equilibrium levels of blood glucose could be established with different infusion rates; the specific rate constants extracted from their data appeared to be independent of the infusion rate. Furthermore, they implied that the rate constants obtained in this manner may exceed those derived by the single injection technique.

\footnotetext{
1 Glucose utilization is defined as the disappearance of blood glucose.

2 The specific rate constant is a proportionality constant defined as the rate of glucose utilization when the concentration is equal to unity (see appendix).
}

The equations cited in the above work have been either empirical or have been derived upon the assumption that the disappearance of blood glucose follows a first order chemical reaction. It is the purpose of this paper to derive a kinetic theory of glucose utilization not involving the above assumption but based upon previous experimental work on the relationship between the level of blood glucose and its utilization (4-8). Experimental evidence will be presented to support this theory along with a study of the behavior of the specific rate constant of glucose utilization.

\section{METHODS AND MATERIALS}

The subjects employed in this study were males between the ages of 21 and 47 , normal with respect to carbohydrate metabolism. The group consisted of resident physicians and hospitalized patients with uncomplicated, non-metabolic illnesses. Each subject received at least $250 \mathrm{gm}$. of dietary carbohydrate daily for three days before the test, but was fasted 14 hours immediately preceding the test. All subjects were at rest in bed throughout the test. The continuous infusion experiments were not begun until the subject had been at bed rest for 30 to 60 minutes.

Venous blood specimens were obtained without stasis from an indwelling venous cannula in the antecubital vein. This vein carries mixed blood from the deep and superficial tissues of the forearm and hand (9). Capillary blood which contains the same glucose concentration as arterial blood (4) was obtained by finger puncture. All blood samples were obtained at 5 or 10 -minute intervals for total test periods ranging from 60 to 180 minutes. Samples were analyzed for glucose by the method of Somogyi-Nelson (10). Care was taken to minimize glycolysis by the use of $\mathrm{NaF}$ and refrigeration. Venous samples were analyzed in duplicate and capillary specimens singly. Duplicate venous samples differed by $2.0 \pm$ 1.8 per cent (mean \pm std. dev.)

In the single injection studies, $25 \mathrm{gm}$. of glucose in 300 $\mathrm{ml}$. of distilled water was injected in $3.5 \pm 0.5$ minutes. The continuous infusion experiments were performed using a Bowman constant infusion pump. Infusion rates in different subjects varied from 1.5 to $6.0 \mathrm{ml}$. per min. of 10 per cent glucose solution. In 24 subjects 10 to $15 \mu \mathrm{c}$. of $\mathrm{Na}^{23}$ was added to the glucose infusion solution. $\mathrm{Na}^{23}$ 


\section{BLOOD GLUCOSE FOLLOWING A SINGLE I.V. GLUCOSE INJECTION}

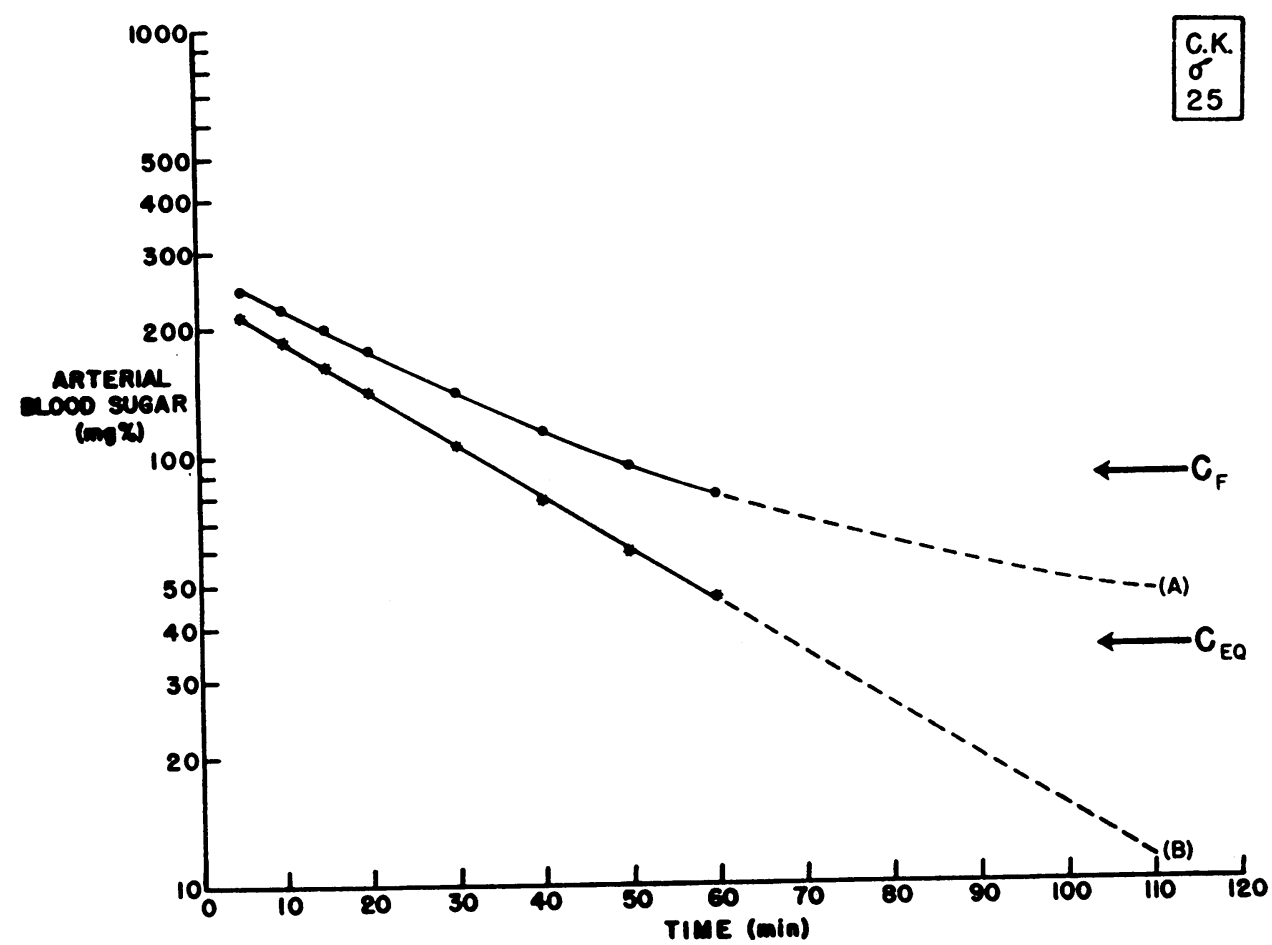

FIgURe 1

Curve (A) represents actual experimental data and is extrapolated to approach an equilibrium level ( $\left.C_{\text {oq }}\right)$ defined here as the experimental fasting level.

Curve (B) is a graphical representation of the analysis of these data according to equation $A-5$ of the appendix. The ordinate in this case represents the difference between the arterial blood glucose concentration $\left(C_{\Delta}\right)$ and $C_{o q}$, but has not been shown for reasons of clarity.

The initial fasting level $\left(C_{r}\right)$ is the arterial blood glucose concentration measured just prior to glucose loading.

radioassay on $2 \mathrm{ml}$. of plasma was accomplished with a R. C. Scientific Scintillation Well Counter.

One hundred and five experiments were done. Of these, 11 were omitted because of poor data. Urine was collected at the end of each experiment and analyzed for total reducing substance by the quantitative Benedict method (11).

\section{RESULTS}

\section{A. Single injection technique}

Twenty-six glucose disappearance curves were obtained from 18 subjects. These curves were analyzed according to the method given in the appendix. An example of this type of experiment with corresponding analysis is shown in Figure 1 and the pertinent results of the analyses of all such experiments are given in Table I. It should be noted in Table $I$ that the mean value of the experimental fasting levels $(62.2 \pm 26.6)$ is significantly below $(P=.001)$ the mean value of the initial fasting levels $(82.2 \pm 7.6)$. Of the individual cases only three values of $\mathrm{C}_{\mathrm{eq}}{ }^{3}$ were well above the corresponding $\mathrm{C}_{\mathrm{F}}{ }^{4}$; in three cases these values were approximately equal; and in the remaining cases, $C_{F}$ exceeded $C_{\text {eq }}$. The specific rate constant for glucose utilization $(\mathrm{K})$ is exemplified in Figure 1 as the slope of curve $B$. The mean value of the specific rate constants $(.0308 \pm .0120)$ as determined here is significantly lower $(\mathrm{P}=$ $.001)$ than that reported by others $(.0370 \pm$ .0054) (2). Also the dispersion of the data is greater. Repeat studies were performed on six

8 The experimental fasting level (see appendix).

4 The initial fasting level (see appendix). 
subjects, and in none of these was the rate constant reproducible. Urine was collected at the end of each experiment and analyzed for total reducing substance. The mean amount recovered for these subjects was $579 \mathrm{mg}$.

\section{B. Continuous infusion technique}

Sixty-nine continuous infusion experiments were done in 63 subjects. The data were analyzed according to the method described in the appendix. Curve $\mathrm{A}$ of Figure 2 represents an example of this type of experiment and curve $B$ exemplifies the corresponding analysis. As in Figure 1, the slope of curve $B$ is the specific rate constant for glucose utilization $(\mathrm{K})$. Table II contains relevant data from all continuous infusion experiments. The mean value of the specific rate constants $(.0400 \pm .0126)$ obtained by this method was significantly higher $(\mathrm{P}=.002)$ than that computed from the data of the single injection method $(.0308 \pm .0120)$, although blood glucose levels in the latter method far exceed those of the former. In two subjects the infusion period was

TABLE I

The results of single glucose injection experiments *

\begin{tabular}{|c|c|c|c|c|}
\hline Subject & $\begin{array}{c}\text { Age } \\
\text { (years) }\end{array}$ & $\underset{(m g \cdot \%)}{\mathrm{C}_{F_{F}}}$ & $\underset{\text { (mg. \%) }}{\mathrm{C}_{\text {og }}}$ & $\underset{(\min .-1)}{\mathrm{K}}$ \\
\hline $\begin{array}{l}\text { H. H. } \\
\text { C. L. } \\
\text { T. W. } \\
\text { T. W. } \\
\text { T. W. } \\
\text { E. H. } \\
\text { B. G. } \\
\text { B. G. } \\
\text { C. G. } \\
\text { J. L. } \\
\text { C. P. } \\
\text { G. C. } \\
\text { G. C. } \\
\text { P. G. } \\
\text { C. K. } \\
\text { G. R. } \\
\text { L. T. } \\
\text { C. A. } \\
\text { F. W. } \\
\text { F. W. } \\
\text { L. R. } \\
\text { L. R. } \\
\text { L. R. } \\
\text { P. M. } \\
\text { L. S. } \\
\text { S. S. }\end{array}$ & $\begin{array}{l}32 \\
30 \\
39 \\
39 \\
39 \\
39 \\
22 \\
22 \\
27 \\
36 \\
36 \\
39 \\
39 \\
32 \\
27 \\
35 \\
45 \\
23 \\
26 \\
26 \\
27 \\
27 \\
27 \\
30 \\
28 \\
28\end{array}$ & $\begin{array}{l}92 \\
80 \\
84 \\
80 \\
92 \\
82 \\
83 \\
86 \\
62 \\
85 \\
71 \\
92 \\
97 \\
72 \\
87 \\
93 \\
76 \\
75 \\
73 \\
72 \\
81 \\
83 \\
88 \\
91 \\
79 \\
82\end{array}$ & $\begin{array}{r}60 \\
70 \\
55 \\
50 \\
70 \\
80 \\
50 \\
60 \\
30 \\
50 \\
85 \\
71 \\
80 \\
150 \\
35 \\
50 \\
62 \\
30 \\
102 \\
75 \\
8 \\
83 \\
55 \\
40 \\
65 \\
50\end{array}$ & $\begin{array}{l}.0243 \\
.0185 \\
.0199 \\
.0227 \\
.0290 \\
.0221 \\
.0320 \\
.0482 \\
.0325 \\
.0155 \\
.0248 \\
.0511 \\
.0272 \\
.0370 \\
.0290 \\
.0194 \\
.0493 \\
.0187 \\
.0400 \\
.0321 \\
.0175 \\
.0467 \\
.0281 \\
.0220 \\
.0309 \\
.0610\end{array}$ \\
\hline Jean & & $\begin{array}{r}82.2 \\
7.6\end{array}$ & $\begin{array}{l}62.2 \\
26.6\end{array}$ & $\begin{array}{l}.0308 \\
.0120\end{array}$ \\
\hline
\end{tabular}

* $C_{\mathbf{F}}$-Initial fasting level. $\mathrm{C}_{\text {oq }}$-Experimental fasting level. $\mathrm{K}$-Specific rate constant for glucose utilization. extended to approximately 150 minutes and in both the specific rate constant remained unchanged over the entire period of the experiments. In five subjects studies were repeated on different days and with a single exception rate constant values could not be reproduced.

From the derivation in the appendix it is possible to compute a theoretical initial fasting level $\left(\mathrm{C}_{\mathrm{F}}{ }^{\prime}\right)$ based upon all the individual measurements of each experiment. A comparison (Table II) between the mean $\mathrm{C}_{\mathrm{F}}^{\prime}(89.8 \pm 7.0)$ and the mean $C_{F}(88.3 \pm 6.7)$ revealed no significant difference $(\mathrm{P}=.42)$.

In another series of experiments, glucose was infused at a constant rate for a 50-minute control period followed by a 40-minute period with the rate of infusion doubled. The latter type of experiment was performed in 17 subjects and the blood glucose level resulting from the doubled infusion rate was approximately 50 per cent above that of the control period. Pertinent data from these experiments are given in Table III and an example with analysis is shown in Figure 3. The striking finding is that the specific rate constant remains unaltered by this procedure; i.e., there is no significant difference $(P=.60)$ between the control periods and those in which the rate of infusion was doubled.

In all continuous infusion experiments, arterial and venous glucose determinations were done. These data have been summarized and the median values are presented in graphic form in Figure 4. It should be noted that although the $C_{A}-C_{\nabla}{ }^{5}$ values are reasonably constant during the control period, there is a significant rise following an increase in the infusion rate.

Urine was collected at the end of each experiment and analyzed for total reducing substance. The mean amount recovered was $314 \mathrm{mg}$. which is negligible compared to the total amount of glucose infused ( 30 to 40 grams).

\section{Volume of distribution}

From the theory given in the appendix it is possible to compute the volume of distribution of glucose. In 68 subjects the mean volume was

${ }^{5} \mathrm{C}_{\Delta}$-The arterial blood glucose concentration. $\mathrm{C}_{\mathrm{F}}$ The venous blood glucose concentration (see the appendix). 


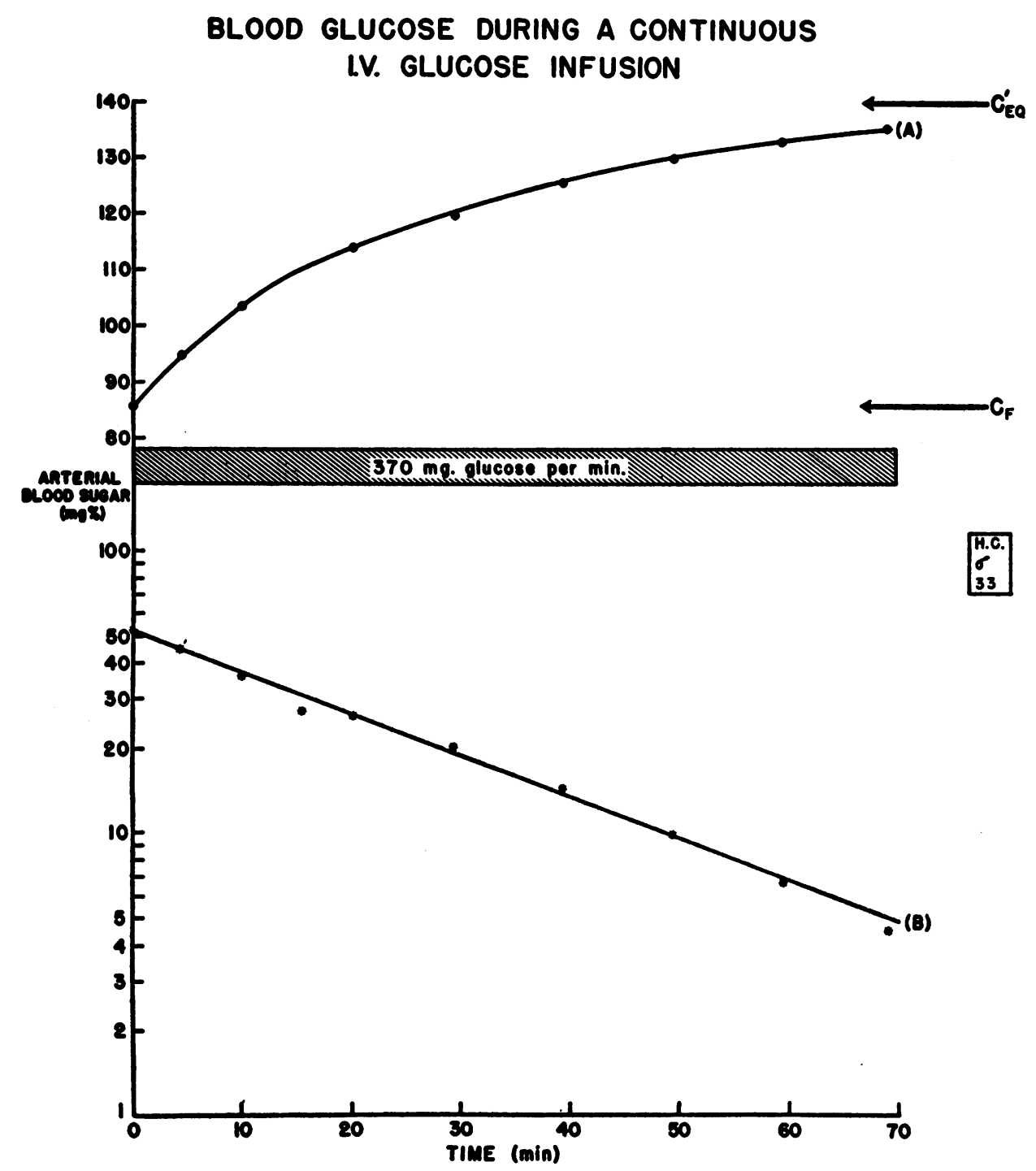

FIGURE 2

Curve (A) represents actual experimental data and is seen to approach an equilibrium level (Coq').

Curve (B) is a graphical representation of the analysis of these data according to equation $B-5$ of the appendix. The ordinate in this case represents the difference between the arterial blood glucose concentration $\left(\mathrm{C}_{\boldsymbol{A}}\right)$ and $\mathrm{C}_{\mathrm{oq}}$ '.

The initial fasting level $\left(C_{w}\right)$ is the arterial blood glucose concentration measured just prior to the beginning of glucose infusion.

$23.3 \pm 6.2$ per cent of body weight (Table II). By employing a similar analysis it was possible to compute the value after the rate of glucose infusion had been doubled. This was done in 17 subjects (Table III) and the mean result was found to be $30.8 \pm 5.9$ per cent of body weight, which is significantly higher $(P=.003)$ than the control value of $24.6 \pm 5.2$ per cent. In other words, an apparent expansion of the available space for glucose distribution occurred subsequent to the increase of the glucose infusion rate.

The above results may have been the result of an increase in extracellular space due to fluid shifts as a consequence of tonicity alteration. This possibility was tested by measuring sodium "space" simultaneously with glucose "space." $\mathrm{Na}^{22}$ was 
added to the infusion fluid and its space of distribution computed according to a method to be described elsewhere (12). Control spaces were computed on 24 of the 68 subjects. In 11 subjects measurements were obtained before and after doubling the rate of the glucose- $\mathrm{Na}^{22}$ infusion. Expressed as percentage of body weight, the mean value of $\mathrm{Na}^{22}$ space during the control periods was $21.4 \pm 3.4$ per cent. The mean value after the increased infusion rate was $22.3 \pm 2.7$ per cent. There was no significant difference $(P=.40)$ between $\mathrm{Na}^{22}$ space before and after the glucose infusion rate was doubled.

\section{DISCUSSION}

The equation described by Amatuzio, Stutzman, Vanderbilt, and Nesbitt (2) is a close approximation of the empirical equation of Greville (1) and the theoretical equation derived here. The data reported in this paper for the single injection tech- nique fit the latter equation as well as that of Greville. These equations are better satisfied when the experimental fasting level is used rather than the initial fasting level. This is evident from (a) the constancy of $K$ throughout the experimental period in any given subject ${ }^{6}$ and (b) the significant difference between the initial and experimental fasting levels in the group of subjects. It would appear that following a rapid glucose load, blood sugar returns to a new level significantly below the initial fasting level (Figure 1). The experimental fasting level is a term of the continuous function (equation $A-5$, appendix)

\footnotetext{
- The data was also analyzed by plotting the logarithm of the difference between the arterial glucose and the initial fasting level vs. time (Amatuzio, Stutzman, Vanderbilt, and Nesbitt, [2]) and by plotting the log of the arterial glucose vs. time (Bastenie, Conard, and Franckson [13]). By either method a constant $K$ may be approximated during the initial experimental period; however, the constancy of $K$ cannot be maintained throughout the complete experimental period.
}

TABLE II

The results of continuous glucose infusion experiments *

\begin{tabular}{|c|c|c|c|c|c|c|c|c|}
\hline Subject & $\begin{array}{c}\text { Age } \\
\text { (years) }\end{array}$ & $\begin{array}{c}\text { Weight } \\
(\mathrm{kg.})\end{array}$ & $\begin{array}{c}\mathrm{R}_{\mathrm{I}} \mathrm{Cl}_{\mathrm{I}} \\
(m g . / m i n .)\end{array}$ & $\begin{array}{c}\mathrm{C}_{F_{\%}} \\
(m g . \%)\end{array}$ & $\begin{array}{c}C_{F_{F}^{\prime}} \\
(m g . \%)\end{array}$ & $\begin{array}{c}\mathrm{C}_{\mathrm{eq}}^{\prime} \\
(m g . \%)\end{array}$ & $\underset{\left(\min \cdot{ }^{-1}\right)}{\mathrm{K}}$ & $\begin{array}{c}\text { Glucose } \\
\text { space } \\
\%\end{array}$ \\
\hline $\begin{array}{l}\text { G. N. } \\
\text { H. C. } \\
\text { C. L. } \\
\text { C. R. } \\
\text { C. F. } \\
\text { P. H. } \\
\text { R. W. } \\
\text { F. R. } \\
\text { J. D. } \\
\text { H. R. } \\
\text { A. S. } \\
\text { B. M. } \\
\text { J. C. } \\
\text { R. W. } \\
\text { E. A. } \\
\text { T. B. } \\
\text { C. H. } \\
\text { V. F. } \\
\text { V. B. } \\
\text { C. B. } \\
\text { B. D. } \\
\text { W. D. } \\
\text { K. R. } \\
\text { G. N. } \\
\text { C. C. } \\
\text { F. R. } \\
\text { J. D. } \\
\text { R. B. } \\
\text { L. T. } \\
\text { R. R. } \\
\text { R. T. } \\
\text { D. D. } \\
\text { G. W. } \\
\text { R. G. } \\
\text { R. B. }\end{array}$ & $\begin{array}{l}35 \\
33 \\
29 \\
31 \\
45 \\
30 \\
27 \\
32 \\
36 \\
41 \\
22 \\
47 \\
28 \\
35 \\
27 \\
35 \\
35 \\
37 \\
31 \\
37 \\
40 \\
27 \\
21 \\
35 \\
46 \\
32 \\
36 \\
47 \\
31 \\
29 \\
30 \\
36 \\
32 \\
36 \\
29\end{array}$ & $\begin{array}{r}65.9 \\
71.8 \\
65.9 \\
69.1 \\
74.1 \\
60.0 \\
56.4 \\
99.6 \\
66.6 \\
94.1 \\
67.3 \\
71.7 \\
64.4 \\
83.6 \\
69.3 \\
71.1 \\
77.3 \\
65.0 \\
70.4 \\
58.9 \\
56.7 \\
85.4 \\
87.7 \\
67.4 \\
71.9 \\
100.0 \\
66.6 \\
69.8 \\
60.4 \\
76.8 \\
60.4 \\
77.7 \\
78.2 \\
69.7 \\
81.6\end{array}$ & $\begin{array}{l}300 \\
295 \\
284 \\
300 \\
317 \\
270 \\
250 \\
330 \\
360 \\
310 \\
280 \\
300 \\
340 \\
250 \\
310 \\
300 \\
305 \\
290 \\
285 \\
345 \\
300 \\
350 \\
360 \\
295 \\
192 \\
260 \\
300 \\
320 \\
310 \\
270 \\
275 \\
300 \\
320 \\
360 \\
360\end{array}$ & $\begin{array}{r}94 \\
81 \\
81 \\
90 \\
101 \\
96 \\
84 \\
87 \\
83 \\
92 \\
86 \\
89 \\
95 \\
81 \\
84 \\
84 \\
81 \\
80 \\
87 \\
83 \\
89 \\
85 \\
77 \\
110 \\
90 \\
79 \\
82 \\
93 \\
89 \\
95 \\
91 \\
87 \\
79 \\
89 \\
88\end{array}$ & $\begin{array}{r}96 \\
81 \\
82 \\
90 \\
102 \\
95 \\
83 \\
87 \\
85 \\
92 \\
86 \\
93 \\
98 \\
80 \\
83 \\
83 \\
89 \\
81 \\
98 \\
80 \\
85 \\
85 \\
89 \\
113 \\
89 \\
80 \\
85 \\
87 \\
90 \\
100 \\
91 \\
87 \\
77 \\
89 \\
93\end{array}$ & $\begin{array}{l}155 \\
112 \\
127 \\
168 \\
185 \\
166 \\
115 \\
135 \\
130 \\
139 \\
130 \\
139 \\
145 \\
112 \\
128 \\
116 \\
144 \\
130 \\
150 \\
191 \\
120 \\
155 \\
143 \\
170 \\
128 \\
103 \\
112 \\
130 \\
133 \\
135 \\
129 \\
135 \\
130 \\
136 \\
145\end{array}$ & $\begin{array}{l}.0300 \\
.0533 \\
.0478 \\
.0277 \\
.0248 \\
.0260 \\
.0520 \\
.0307 \\
.0310 \\
.0336 \\
.0340 \\
.0317 \\
.0420 \\
.0639 \\
.0399 \\
.0730 \\
.0435 \\
.0335 \\
.0310 \\
.0260 \\
.0470 \\
.0333 \\
.0265 \\
.0340 \\
.0200 \\
.0825 \\
.0530 \\
.0313 \\
.0565 \\
.0295 \\
.0430 \\
.0320 \\
.0294 \\
.0557 \\
.0395\end{array}$ & $\begin{array}{l}25.7 \\
24.5 \\
19.8 \\
20.0 \\
20.8 \\
24.4 \\
26.7 \\
22.6 \\
38.8 \\
21.2 \\
29.7 \\
28.7 \\
26.7 \\
14.5 \\
21.1 \\
17.5 \\
16.4 \\
27.2 \\
25.1 \\
20.3 \\
32.2 \\
17.4 \\
28.7 \\
22.4 \\
34.1 \\
13.4 \\
30.9 \\
33.7 \\
21.3 \\
34.2 \\
27.8 \\
25.1 \\
26.0 \\
19.5 \\
21.5\end{array}$ \\
\hline
\end{tabular}


TABLE II-Continued

\begin{tabular}{|c|c|c|c|c|c|c|c|c|}
\hline Subject & $\underset{(\text { years) }}{\text { Age }}$ & $\begin{array}{c}\text { Weight } \\
(\mathrm{kg.})\end{array}$ & $\underset{(m g . / m i n .)}{\mathrm{Ri}_{1} \mathrm{Cl}_{\mathbf{I}}}$ & $\underset{(m g . \%)}{\mathrm{C}_{\mathbf{F}}}$ & $\underset{(m g . \%)}{C_{\mathbf{F}^{\prime}}^{\prime}}$ & $\underset{(m g . \%)}{C_{60^{\prime}}}$ & $\underset{\left(\min .^{-1}\right)}{\mathbf{K}}$ & $\begin{array}{c}\text { Glucose } \\
\text { space } \\
\%\end{array}$ \\
\hline $\begin{array}{l}\text { C. J. } \\
\text { E. J. } \\
\text { J.P. } \\
\text { W. Y. } \\
\text { G. M. } \\
\text { W. F. } \\
\text { H. C. } \\
\text { L.S. } \\
\text { F.A. } \\
\text { L. M. } \\
\text { V.O. } \\
\text { H. E. } \\
\text { L. D. } \\
\text { R.S. } \\
\text { P.W. } \\
\text { W. H. } \\
\text { J. C. } \\
\text { J.H. } \\
\text { A. M. } \\
\text { E. R. } \\
\text { W. D. } \\
\text { A.T. } \\
\text { J.S. } \\
\text { J.G. } \\
\text { R. R. } \\
\text { J. C. } \\
\text { E. H. } \\
\text { T. D. } \\
\text { A. O. } \\
\text { M. A. } \\
\text { C. R. } \\
\text { F. R. } \\
\text { C. G. } \\
\text { R. B. }\end{array}$ & $\begin{array}{l}26 \\
25 \\
31 \\
22 \\
22 \\
32 \\
33 \\
24 \\
22 \\
22 \\
29 \\
29 \\
33 \\
32 \\
21 \\
24 \\
32 \\
21 \\
27 \\
23 \\
36 \\
39 \\
38 \\
26 \\
29 \\
34 \\
37 \\
37 \\
43 \\
34 \\
23 \\
29 \\
30 \\
47\end{array}$ & $\begin{array}{l}70.7 \\
79.0 \\
65.0 \\
77.8 \\
60.0 \\
53.2 \\
71.8 \\
64.6 \\
67.1 \\
60.9 \\
65.0 \\
65.5 \\
63.1 \\
71.1 \\
66.8 \\
58.6 \\
70.5 \\
61.1 \\
87.7 \\
75.7 \\
69.6 \\
68.2 \\
79.1 \\
53.9 \\
75.0 \\
80.5 \\
73.3 \\
68.4 \\
73.6 \\
67.8 \\
71.1 \\
60.5 \\
60.5 \\
69.8\end{array}$ & $\begin{array}{l}370 \\
360 \\
360 \\
344 \\
365 \\
325 \\
370 \\
360 \\
220 \\
330 \\
290 \\
320 \\
300 \\
300 \\
270 \\
300 \\
295 \\
270 \\
250 \\
310 \\
277 \\
320 \\
300 \\
275 \\
290 \\
290 \\
270 \\
265 \\
320 \\
390 \\
310 \\
275 \\
270 \\
300\end{array}$ & $\begin{array}{r}86 \\
86 \\
80 \\
88 \\
87 \\
75 \\
86 \\
86 \\
80 \\
83 \\
81 \\
99 \\
88 \\
92 \\
101 \\
84 \\
93 \\
93 \\
91 \\
90 \\
89 \\
101 \\
95 \\
90 \\
95 \\
90 \\
92 \\
106 \\
89 \\
97 \\
82 \\
87 \\
83 \\
84\end{array}$ & $\begin{array}{r}86 \\
89 \\
86 \\
93 \\
86 \\
86 \\
98 \\
90 \\
89 \\
79 \\
82 \\
98 \\
92 \\
93 \\
101 \\
84 \\
92 \\
95 \\
91 \\
89 \\
89 \\
102 \\
97 \\
90 \\
103 \\
90 \\
93 \\
105 \\
87 \\
98 \\
80 \\
91 \\
84 \\
88\end{array}$ & $\begin{array}{l}165 \\
132 \\
154 \\
140 \\
173 \\
144 \\
140 \\
135 \\
118 \\
149 \\
133 \\
185 \\
145 \\
165 \\
146 \\
150 \\
160 \\
143 \\
122 \\
153 \\
140 \\
175 \\
170 \\
147 \\
145 \\
143 \\
132 \\
160 \\
140 \\
180 \\
145 \\
132 \\
115 \\
132\end{array}$ & $\begin{array}{l}.0238 \\
.0404 \\
.0303 \\
.0390 \\
.0333 \\
.0263 \\
.0330 \\
.0412 \\
.0475 \\
.0470 \\
.0495 \\
.0331 \\
.0395 \\
.0394 \\
.0354 \\
.0532 \\
.0591 \\
.0406 \\
.0310 \\
.0285 \\
.0442 \\
.0196 \\
.0465 \\
.0394 \\
.0298 \\
.0447 \\
.0604 \\
.0532 \\
.0266 \\
.0372 \\
.0366 \\
.0688 \\
.0526 \\
.0410\end{array}$ & $\begin{array}{l}27.8 \\
26.2 \\
26.7 \\
23.9 \\
21.0 \\
33.7 \\
30.0 \\
30.1 \\
23.8 \\
16.5 \\
17.7 \\
17.0 \\
22.5 \\
14.8 \\
25.1 \\
14.6 \\
10.4 \\
22.7 \\
29.5 \\
22.4 \\
17.5 \\
32.6 \\
11.1 \\
22.7 \\
30.7 \\
15.2 \\
15.5 \\
13.2 \\
30.8 \\
18.9 \\
18.3 \\
16.1 \\
27.6 \\
23.9\end{array}$ \\
\hline $\begin{array}{l}\text { Mean values } \\
\text { Std. deviation }\end{array}$ & & & & $\begin{array}{r}88.3 \\
6.7\end{array}$ & $\begin{array}{r}89.8 \\
7.0\end{array}$ & & $\begin{array}{l}.0400 \\
.0126\end{array}$ & $\begin{array}{r}23.3 \\
6.3\end{array}$ \\
\hline
\end{tabular}

* $R_{\mathrm{r}}$-Rate of infusion (ml./min.). $\mathrm{C}_{\mathrm{I}}$-Concentration of infused fluid (mg./ml.). $\mathrm{C}_{\mathrm{F}}$-Initial fasting level. $\mathrm{C}_{\mathbf{F}}$-Theoretical initial fasting level. $\mathrm{C}_{\mathrm{eq}}{ }^{\prime}-\mathrm{Blood}$ glucose level at equilibrium $(\mathrm{t}=\infty)$. $\mathrm{K}-\mathrm{Specific}$ rate constant for glucose utilization. Glucose space-The volume of distribution of glucose expressed as per cent of body weight.

describing glucose disappearance from a loaded system. This level serves as reference level for a new physiologic state following the glucose load. It should be noted that this new state is apparently steady throughout the disappearance phase of blood glucose, but that it is different from the basal state. The fact that the new level was usually below the initial level is compatible with the hypoglycemia commonly observed following rapid glucose loading. It is also common knowledge that blood sugar will eventually return to the initial fasting level following the hypoglycemic phase. Thus it is apparent that the new state created by the glucose load is not persistent. It should be emphasized that although equation $A-5$ describes blood glucose to the minimum hypoglycemia, it is not intended to describe the return phase which represents a change in the state of the system.
In contrast to the sudden elevation of blood glucose resulting from a single glucose injection, blood glucose levels were increased gradually with the continuous infusion method. The equation $(B-5)$ given here is well satisfied by the experimental data. In the continuous infusion experiments there was no significant difference between the initial fasting level and the computed initial fasting level. This computed level is derived from all the measurements of each experiment. Since these levels are statistically identical a more stable state is apparently maintained throughout continuous glucose infusion, resulting in less disturbance to the glucose regulation mechanisms. It is probable that the rate constant derived by the continuous infusion method is more characteristic of the basal physiologic state.

There is considerable evidence in animals that 
hyperglycemia resulting from glucose loading, it has been shown in humans by direct insulin asstimulates endogenous insulin release (14-16). say that alimentary hyperglycemia results in a However, it is difficult to compare these experi- mean increase of 600 per cent in plasma-insulin ments to the present ones since the former were activity one hour after the ingestion of $50 \mathrm{gm}$. of done at much higher blood sugar levels. Recently, glucose (17). Using the same authors' data, this

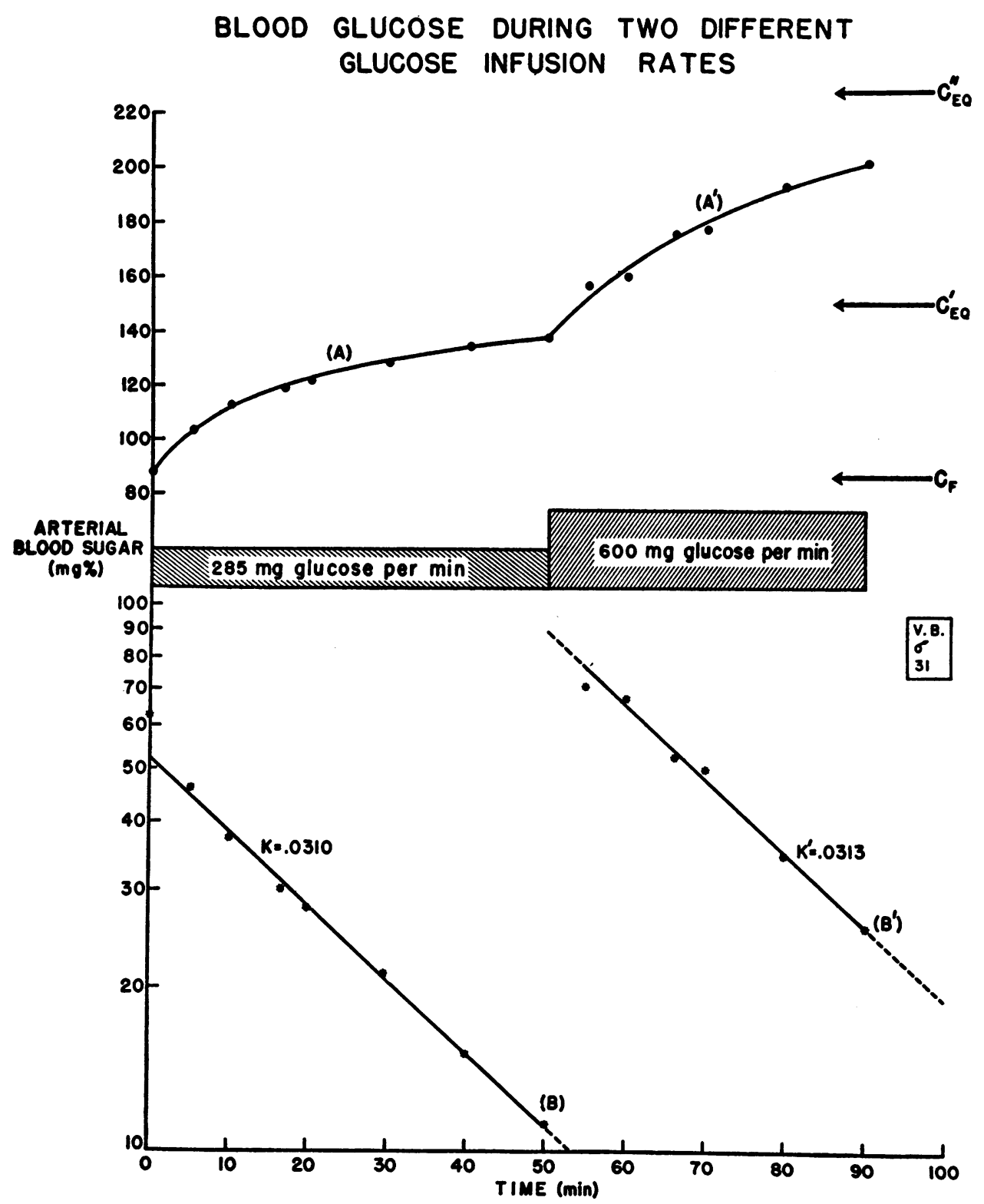

FIGURE 3

Curves $A$ and $A^{\prime}$ represent actual experimental data with their respective equilibrium levels at $\mathrm{C}_{\text {eq' }}$ and $\mathrm{C}_{\text {oq }}{ }^{\prime \prime}$.

Curves $B$ and $\mathrm{B}^{\prime}$ represent the analysis of these data according to equation $B-5$ of the appendix. The ordinate in this case represents the difference between the arterial blood glucose concentration $\left(C_{\Delta}\right)$ and the respective equilibrium level.

The initial fasting level $\left(C_{F}\right)$ is the arterial blood glucose concentration measured just prior to glucose infusion. 
TABLE III

The results of continuous glucose infusion experiments with elevated infusion rates *

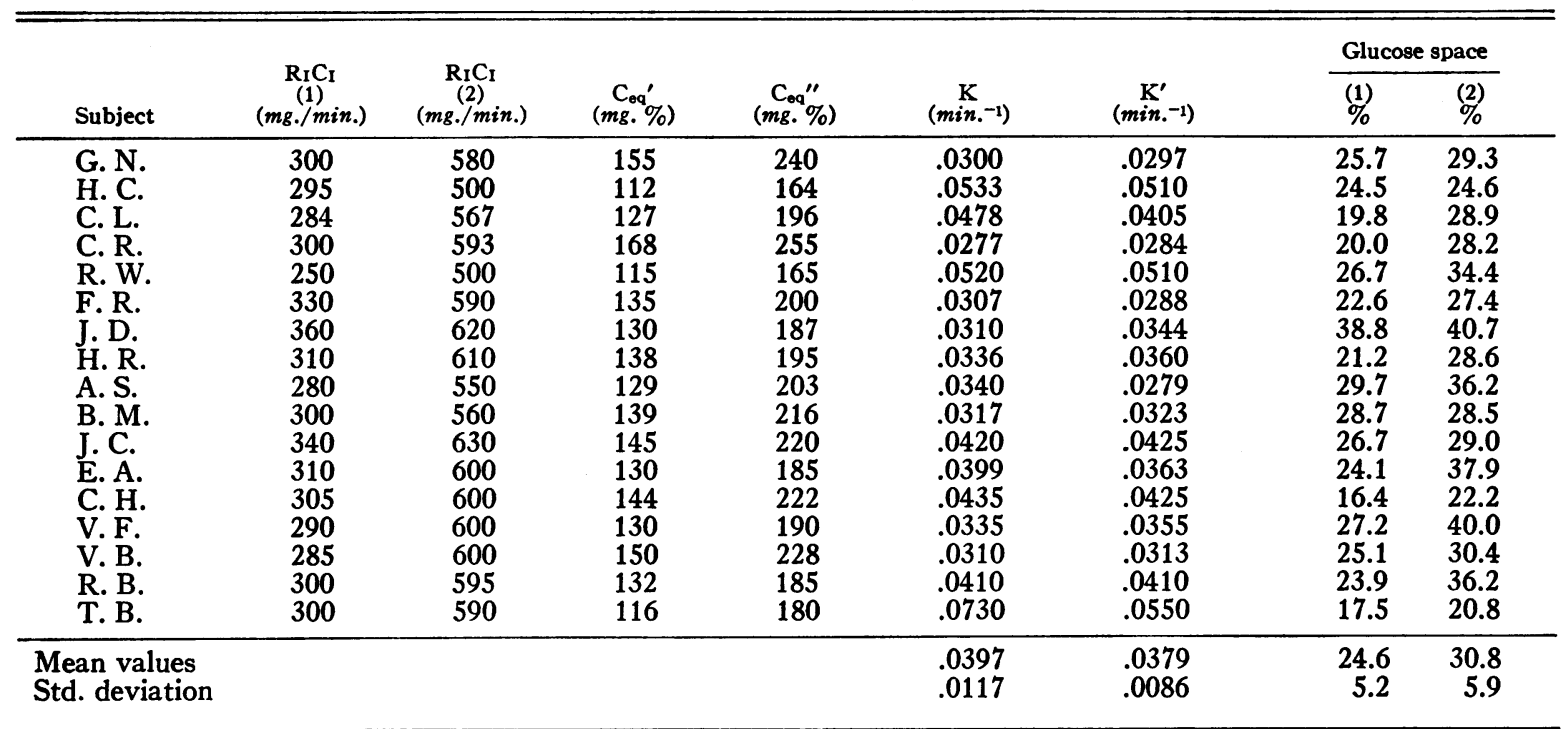

* $\mathrm{R}_{\mathrm{I}} \mathrm{C}_{\mathrm{I}}$ (1)-Initial rate of glucose infusion. $\mathrm{R}_{I} \mathrm{C}_{\mathrm{I}}(2)$-Final rate of glucose infusion. $\mathrm{C}_{e q}$ - $-\mathrm{Blood}$ glucose level at equilibrium $(t=\infty)$ associated with the initial infusion rate. $C_{e q}{ }^{\prime \prime}-B$ lood glucose level at equilibrium $(t=\infty)$ associated with the final infusion rate. $\mathrm{K}$-Specific rate constant for glucose utilization associated with initial infusion rate. $K^{\prime}$-Specific rate constant for glucose utilization associated with final infusion rate. Glucose Space-Volume of distribution of glucose associated with the initial (1) and final (2) infusion rates. These values are expressed as per cent of body weight. Ages and weights of this group may be found in Table II.

\section{THE EFFECT OF TWO DIFFERENT \\ GLUCOSE INFUSION RATES ON $k_{p}$}

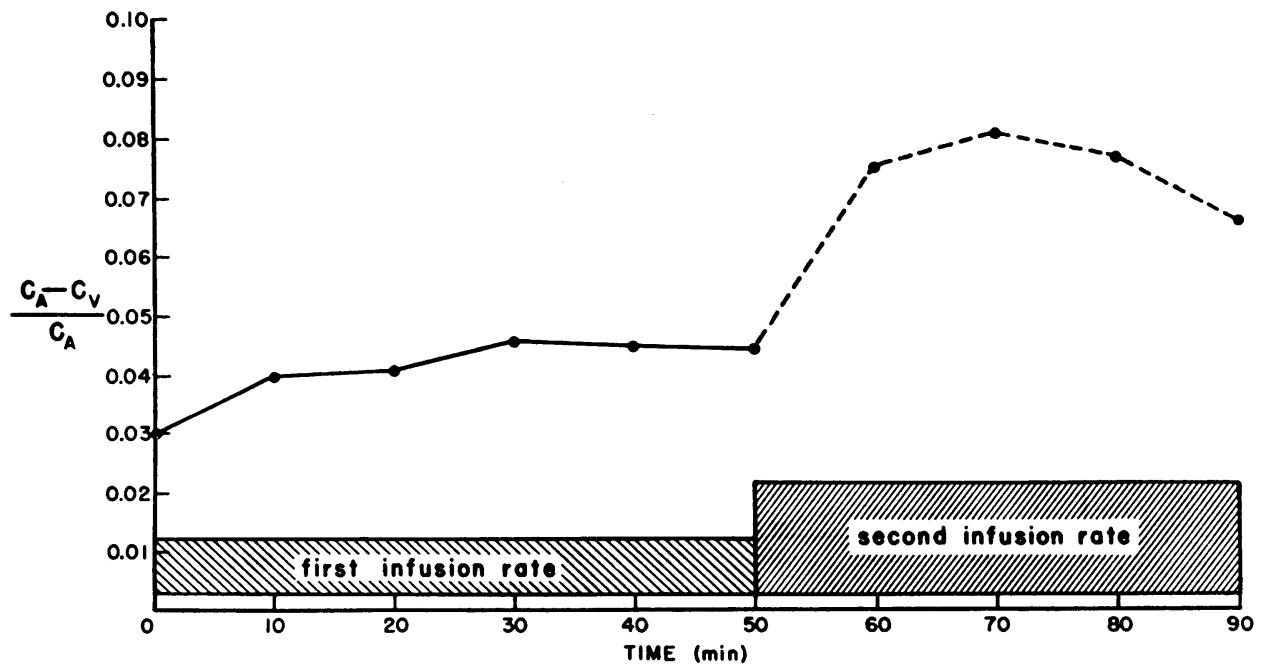

FIgURe 4

The ordinate $\left(C_{A}-C_{\nabla} / C_{A}\right)$ is shown in the appendix to be a measure of the specific rate constant $\left(k_{p}\right)$ for peripheral glucose utilization and represents the arterio-venous glucose difference divided by the arterial blood glucose concentration. The plotted data represent median values determined from 17 experiments. 
is equivalent to the addition of 4.8 units of insulin in an average man. It has been reported (18) and substantiated by work in this laboratory (19) that small amounts (2.5 to 4 units) of exogenous insulin will cause a striking increase in the specific rate constant. It was, therefore, surprising to observe that the mean specific rate constant obtained from the sudden loading technique is significantly lower than that obtained from the continuous infusion technique. It would appear that of the two methods for adding glucose to the system, the sudden loading technique with its resulting higher blood sugars is more likely to stimulate insulin release and thus more likely to increase the specific rate constants.

With the constant infusion technique it was possible to determine whether or not an elevated blood sugar alters the specific rate constant in the same patient. The results of the experiments in which the glucose infusion rate was doubled following the control period showed that no significant difference exists between the specific rate constants of the control and experimental periods (Table III). Furthermore, K remained constant throughout each phase of these experiments. If insulin secretion is a function of blood glucose, one might expect an ever increasing $\mathrm{K}$ value with rising glucose levels.

Thus, under the conditions of these experiments, by either single injection or continuous infusion of glucose, no evidence was obtained to support the concept that intravenous hyperglycemia stimulates the secretion of extra insulin. These findings suggest that the liver rather than the pancreas is responsible for the minute-to-minute regulation of blood sugar level. They are in agreement with previous evidence that extra insulin is not required for the adequate disposal of an intravenous glucose load in the depancreatized dog $(20$, 21).

The volume of distribution of glucose is obviously complex. Possibly the best definition of this "space" as measured here is that which is occupied by "exchangeable" glucose. The apparent increase in glucose "space" with elevated blood glucose is not explained by a simple fluid shift, since $\mathrm{Na}^{22}$ space remained constant. One might speculate that since the specific rate constant is unaltered, and $\mathrm{Na}^{22}$ space remains constant, the observed increase in glucose "space" is a change associated with increased cellular metabolism of glucose.

A derivation is given in the appendix which shows that $\left(C_{A}-C_{V} / C_{A}\right)$ is proportional to the specific rate constant of peripheral glucose utilization $\left(k_{p}\right)$ under certain conditions. An examination of Figure 4 shows that elevation of the glucose infusion rate results in an elevation of this variable $\left(C_{A}-C_{\nabla} / C_{A}\right)$. It has been shown that the total disappearance rate constant $(\mathrm{k})$ remains unaltered throughout this procedure and that the volume of distribution increases. This would be the predicted behavior of these variables to account for the rise in the $\left(C_{A}-C_{V} / C_{A}\right)$ values.

\section{SUM MARY}

Some theoretical aspects of the kinetics of glucose utilization and a method for computation of glucose "space" are described. One hundred five studies were performed in 81 normal men using either a single injection or continuous infusion technique. Data are presented which support the derived equations. No evidence was obtained to indicate that excess insulin is released in response to the intravenous administration of glucose. The volume of distribution of glucose is discussed and evidence is presented which suggests an expansion of this "space" with increased blood sugar levels.

\section{APPENDIX}

Lang, Goldstein, and Levine reported that peripheral glucose utilization in the normal dog is a linear function of arterial blood glucose over a wide range (79 to $645 \mathrm{mg}$. per cent) of blood glucose values (6). The data were obtained in what may be considered as a steady physiological state (constant infusion of glucose). Prior to this, Soskin and Levine had established a proportionality between peripheral glucose utilization and blood sugar which was linear between blood sugar levels of 100 and $400 \mathrm{mg}$. per cent (5). The latter data were obtained in the eviscerated dog in a steady state. Somogyi obtained careful measurements of arterial blood sugars and corresponding arteriovenous differences in man before and after the oral ingestion of $100 \mathrm{gm}$. of glucose (4). Although blood flow was not measured, there was a linear correlation between $\mathrm{A}-\mathrm{V}$ difference and arterial blood level during the disappearance phase of blood glucose.

This evidence indicates that in both steady and quasisteady states, glucose utilization is a linear function of arterial blood glucose over a wide range of blood glucose levels. The range of blood glucose values in the present study is within the range over which linearity has been demonstrated. The linear function described above may 
be expressed as follows :

$$
\mathrm{U}_{\mathrm{P}}=\mathrm{k}_{\mathrm{p}} \cdot \mathrm{G}_{\mathrm{A}}
$$

where $U_{P}$ represents the rate of peripheral utilization of glucose; $k_{p}$ the specific rate constant associated with peripheral utilization; and $G_{A}$ the total glucose presented to the peripheral cells for metabolism at any time.

The rate of peripheral utilization of glucose may also be expressed as:

$$
\mathrm{U}_{\mathrm{P}}=\mathrm{R}\left(\mathrm{C}_{\mathrm{A}}-\mathrm{C}_{\mathrm{V}}\right) \text {. }
$$

where $R$ is the arterial blood flow rate and $C_{A}$ and $C_{V}$ are the arterial and venous glucose concentrations, respectively. Combining equations 1 and 2 and solving for $k_{p}$ results in :

$$
k_{p}=\frac{C_{A}-C_{V}}{C_{A}} \cdot \frac{R}{V},
$$

where $\mathrm{V}$ is the volume of distribution of $\mathrm{G}_{\mathrm{A}}$. It should be noted that if $\mathrm{R}$ and $\mathrm{V}$ remain constant, $\mathrm{k}_{\mathrm{p}}$ is proportional to $\frac{\mathrm{C}_{\mathbf{A}}-\mathrm{C}_{\mathbf{V}}}{\mathrm{C}_{\mathbf{A}}}$.

Soskin, Essex, Herrick, and Mann (7) showed that liver uptake or output of glucose is related to the arterial glucose level. This work was done in the dog using both a single injection and a continuous infusion of glucose. By replotting their data it is possible to show that liver uptake or output of glucose is a linear function of arterial blood glucose. Bondy, James, and Farrar reported similar results in man (8). Analysis of their data reveals that a linear correlation exists between the mean values of $A-V$ difference across the liver and mean values of arterial blood glucose. Thus it appears that in the dog and the human the liver uptake or output of glucose can be considered to be a linear function of arterial glucose level. This function may be expressed as follows:

$$
\mathrm{U}_{\mathbf{L}}=-\mathrm{mG}_{\mathbf{A}}+\mathrm{b},
$$

where $U_{L}$ represents the rate of uptake or output of glucose by the liver $\left(U_{L}>0\right.$; output $U_{L}<0$; uptake); and $m$ and b are constants characteristic of the state of the system. With these two equations it is possible to derive ideal relationships which govern the behavior of blood glucose either subsequent to sudden glucose loading or during the continuous infusion of glucose.

\section{A. Sudden glucose injection}

Previous work in man indicates that blood glucose disappearance after a single intravenous glucose load follows an exponential function shortly after the peak blood glucose level $(1,2,9)$. In these experiments adequate mixing is apparently obtained within 10 minutes after the glucose injection. This function also implies that the system does not deviate too far from a steady state during glucose disappearance. At fasting equilibrium when the blood sugar level is constant, it may be stated that:

$$
\mathrm{U}_{\mathrm{L}} \geqslant 0, \quad \mathrm{U}_{\mathrm{P}} \geqslant 0 \text { and } \mathrm{U}_{\mathrm{L}}=\mathrm{U}_{\mathrm{P}} \text {. }
$$

But following a sudden glucose load this equilibrium is upset and the liver responds in such a manner that:

$$
\mathrm{U}_{\mathbf{L}}<0 \text { and } \mathrm{U}_{\mathrm{P}}>0
$$

then, subsequent to adequate mixing:

$\frac{d G_{A}}{d t}=U_{L}-U_{P}=-m_{A}+b-k_{p} G_{A}$

$$
=-\mathrm{KG}_{\mathbf{A}}+\mathrm{b} \text {, }
$$

where $K$ represents the specific rate constant for glucose disappearance from the blood and is associated with the total utilization of glucose. Upon integration:

$$
\left[\ln \left(\mathrm{b}-\mathrm{KG}_{\mathrm{A}}\right)\right]_{\mathrm{G}_{0}}^{\mathrm{G}_{\mathbf{A}}}=[-\mathrm{Kt}]_{0}^{\mathrm{t}} \text {, }
$$

where $G_{0}$ is the value of $G_{A}$ at $t=0$ which is defined at the point where mixing is complete. Evaluation of $A-2$ :

$$
\begin{aligned}
b-K G_{A} & =\left(b-K G_{0}\right) e^{-K t} \\
\text { At } t=\infty, \quad G_{A} & =G_{\text {eq }}, \text { and } \frac{b}{K}=G_{\bullet q}
\end{aligned}
$$

$\mathrm{G}_{\mathrm{oq}}$ represents the theoretical glucose content at $\mathrm{t}=\infty$. Upon substitution $A-3$ becomes :

$$
\mathrm{G}_{A}-\mathrm{G}_{\mathrm{eq}}=\left(\mathrm{G}_{0}-\mathrm{G}_{\mathrm{eq}}\right) \mathrm{e}^{-\mathrm{Kt}} \text {. }
$$

In concentration form for a constant volume of distribution, $A-4$ becomes:

$$
C_{A}-C_{\text {eq }}=\left(C_{0}-C_{\theta q}\right) e^{-K t} \text {, }
$$

where $C_{A}$ is the arterial blood glucose concentration at any time $(t) ; C_{e q}$ is equilibrium blood glucose level and should be equivalent to the initial fasting level $\left(C_{F}\right)$ providing the state of the system remains stable as a consequence of glucose loading; and $\mathrm{C}_{0}$ is the concentration associated with $G_{0}$. It should be noted that a plot of $C_{A}-C_{0 q}$ versus $t$ on semilogarithmic paper results in a straight line with a zero intercept of $\mathrm{C}_{0}-\mathrm{C}_{\text {eq. }}$. This is exemplified by curve $B$ of Figure 1 .

\section{B. Continuous glucose infusion}

In the non-equilibrium state during continuous glucose infusion,

$$
\mathrm{R}_{\mathrm{I}} \mathrm{C}_{\mathrm{I}}+\mathrm{U}_{\mathrm{L}}>\mathrm{U}_{\mathbf{P}} \text {, }
$$

where $R_{I}$ is the rate of infusion and $C_{I}$ is the infused glucose concentration. Then :

$$
\begin{aligned}
\frac{d G_{A}}{d t}=R_{I} C_{I}-m G_{A}+b- & k_{p} G_{A} \\
& =R_{I} C_{I}+b-K G_{A} .
\end{aligned}
$$

Upon integration :

$$
\left[\ln \left(\mathrm{R}_{\mathrm{I}} \mathrm{C}_{\mathrm{I}}+\mathrm{b}-\mathrm{KG}_{\mathrm{A}}\right)\right]_{\mathrm{GF}_{\mathbf{A}}^{\prime}}^{\mathrm{G}_{\mathbf{A}}}=[-\mathrm{Kt}]_{0}^{\mathrm{t}},
$$

where $G_{F^{\prime}}^{\prime}$ is the value of $G_{A}$ at $t=0$ and is theoretically equivalent to the glucose content at fasting equilibrium preceding glucose infusion. Evaluating $B-2$ :

$$
\begin{aligned}
& \mathrm{R}_{\mathrm{I}} \mathrm{C}_{\mathrm{I}}+\mathrm{b}-\mathrm{KG}_{\mathbf{A}}=\left(\mathrm{R}_{\mathrm{I}} \mathrm{C}_{\mathrm{I}}+\mathrm{b}-K \mathrm{G}_{\mathrm{F}}^{\prime}\right) \mathrm{e}^{-\mathrm{Kt}} \quad(B-3) \\
& \text { At } \mathrm{t}=\infty, \mathrm{G}_{\mathbf{A}}=\mathrm{G}_{\text {oq }}^{\prime} \text { and } \mathrm{b}=K \mathrm{G}_{\text {oq }}^{\prime}-\mathrm{R}_{\mathrm{I}} \mathrm{C}_{\mathrm{I}},
\end{aligned}
$$

where $G^{\prime}$ oq is the equilibrium glucose content at $t=\infty$ and after substitution, $B-3$ becomes:

$$
G_{\text {oq }}^{\prime}-G_{A}=\left(G_{\text {oq }}^{\prime}-G_{r}^{\prime}\right) e^{-K t} \text {. }
$$

In concentration form, $B-4$ becomes :

$$
C_{\text {oq }}^{\prime}-C_{A}=\left(C_{\text {oq }}^{\prime}-C_{F}^{\prime}\right) e^{-K t} \text {, }
$$

where $C^{\prime}$ oq is the eventual equilibrium glucose level at $t=\infty$ and $C^{\prime} F$ is the theoretical initial fasting level. It 
should be noted that a plot of $C_{\text {oq }}^{\prime}-C_{A}$ versus $t$ on semilogarithmic paper results in a straight line with a zero intercept of $C_{\text {eq }}^{\prime}-C_{F}^{\prime}$. This is exemplified by curve $B$ of Figure 2. Furthermore, $\mathrm{C}_{\boldsymbol{F}^{\prime}}$ is observable after the zero intercept is established.

\section{Volume of distribution}

Within the limits defined here, the slope of equation $B-5$ is a maximum at $\mathrm{t}=0$ and a minimum at $\mathrm{t}=\infty$. The maximum slope $\left(S_{\max }\right)$ may be evaluated as:

$$
S_{\max }=K\left(C_{\text {eq }}^{\prime}-C_{r}^{\prime}\right) \text {. }
$$

If a negligible volume of glucose is infused into a system of constant volume and no process takes place other than distribution of the infused glucose, the concentration within the constant volume will increase as a linear function of time. The slope of this function is equivalent to $\frac{R_{I} C_{I}}{V}$. Since the infused glucose is the only exogenous glucose added to the system and since $U_{L} \geqslant 0$ only at fasting equilibrium, it may be assumed that the maximum change in blood glucose results from the infused glucose. Thus the slope due to infusion alone is the limiting value of the slope of equation $B-5$. Therefore:

$$
\frac{\mathrm{R}_{\mathrm{I}} \mathrm{C}_{\mathrm{I}}}{\mathrm{V}}=\mathrm{K}\left(\mathrm{C}_{\mathrm{eq}}{ }^{\prime}-\mathrm{C}_{\mathrm{F}}{ }^{\prime}\right)
$$

and solving for $\mathrm{V}$ :

$$
V=\frac{R_{I} C_{I}}{K\left(C_{\circ q}^{\prime}-C_{F}^{\prime}\right)}
$$

\section{ACKNOWLEDGMENTS}

The authors wish to acknowledge the helpful suggestions of Dr. J. H. Holmes, Dr. C. Mackenzie, and Dr. T. Puck.

\section{REFERENCES}

1. Greville, G. D., The intravenous glucose tolerance equation. Biochem. J., 1943, 37, 17.

2. Amatuzio, D. S., Stutzman, F. L., Vanderbilt, M. J., and Nesbitt, S., Interpretation of the rapid intravenous glucose tolerance test in normal individuals and in mild diabetes mellitus. J. Clin. Invest., 1953, $32,428$.

3. Jokipii, S. G., and Turpeinen, O., Kinetics of elimination of glucose from the blood during and after a continuous intravenous injection. J. Clin. Invest., 1954, 33, 452.

4. Somogyi, M., Studies of arteriovenous differences in blood sugar. I. Effect of alimentary hyperglycemia on the rate of extrahepatic glucose assimilation. J. Biol. Chem., 1948, 174, 189.

5. Soskin, S., and Levine, R., A relationship between the blood sugar level and the rate of sugar utilization, affecting the theories of diabetes. Am. J. Physiol., 1937, 120, 761.
6. Lang, S., Goldstein, M. S., and Levine, R., Influence of the liver on uptake of glucose by extrahepatic tissues. Am. J. Physiol., 1954, 177, 447.

7. Soskin, S., Essex, H. E., Herrick, J. F., and Mann, F. C., The mechanism of regulation of the blood sugar by the liver. Am. J. Physiol., 1938, 124, 558.

8. Bondy, P. K., James, D. F., and Farrar, B. W., Studies of the role of the liver in human carbohydrate metabolism by the venous catheter technic. I. Normal subjects under fasting conditions and following the injection of glucose. J. Clin. Invest., 1949, 28, 238.

9. Gray, H., Anatomy of the Human Body, C. M. Goss, Ed., 26th ed., Philadelphia, Lea Febiger, 1954, p. 737.

10. Nelson, N., A photometric adaptation of the Somogyi method for the determination of glucose. J. Biol. Chem., 1944, 153, 375.

11. Todd, J. C., and Sanford, A. H., Clinical Diagnosis by Laboratory Methods; A working manual of clinical pathology. 10th ed., Philadelphia, W. B. Saunders Co., 1943, p. 101.

12. Hlad, C. J., Elrick, H., Huffman, E., and Whipple, $\mathrm{N}$., Studies on $\mathrm{Na}^{23}$ space in man. (To be published.)

13. Bastenie, P. A., Conard, V., and Franckson, J. R. M., Effect of cortisone on carbohydrate metabolism measured by the "glucose assimilation coefficient." Diabetes, 1954, 3, 205.

14. Brown, E. M., Jr., Dohan, F. C., Freedman, L. R., DeMoor, P., and Lukens, F. D. W., The effects of prolonged infusion of the dog's pancreas with glucose. Endocrinology, 1952, 50, 644.

15. Anderson, E., and Long, J. A., The effect of hyperglycemia on insulin secretion as determined with the isolated rat pancreas in a perfusion apparatus. Endocrinology, 1947, 40, 92.

16. Foglia, V.-G., and Fernandez, R., Action directe du glucose sur la secretion de l'insuline par le pancreas. Compt. rend. Soc. de biol., 1936, 121, 355.

17. Vallance-Owen, J., and Hurlock, B., Estimation of plasma-insulin by the rat diaphragm method. Lancet, 1954, 1, 68.

18. Amatuzio, D. S., Schultz, A. L., Vanderbilt, M. J., Rames, E. D., and Nesbitt, S., The effect of epinephrine, insulin, and hyperthyroidism on the rapid intravenous glucose tolerance test. J. Clin. Invest., $1954,33,97$.

19. Witten, T., Insulin sensitivity in cirrhosis. Am. J. Physiol., 1954, 179, 685.

20. Soskin, S., Allweiss, M. D., and Cohn, D. J., Influence of the pancreas and the liver upon the dextrose tolerance curve. Am. J. Physiol., 1934, 109, 155.

21. Soskin, S., and Allweiss, M. D., The hypoglycemic phase of the dextrose tolerance curve. Am. J. Physiol., 1934, 110, 4. 